\title{
Non-linearities and persistence in US long-run interest rates
}

\section{Guglielmo Maria Caporale, Luis Alberiko Gil-Alana \& Miguel Ángel Martin- Valmayor}

To cite this article: Guglielmo Maria Caporale, Luis Alberiko Gil-Alana \& Miguel Ángel MartinValmayor (2021): Non-linearities and persistence in US long-run interest rates, Applied Economics Letters, DOI: $10.1080 / 13504851.2021 .1897511$

To link to this article: https://doi.org/10.1080/13504851.2021.1897511

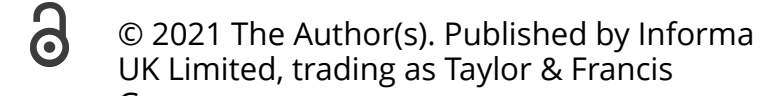
Group.

\section{曲 Published online: 09 Mar 2021.}

Submit your article to this journal $\llbracket$

Џ Article views: 279

Q View related articles

View Crossmark data $\asymp$ 


\title{
Non-linearities and persistence in US long-run interest rates
}

\author{
Guglielmo Maria Caporale ${ }^{\mathrm{a}}$, Luis Alberiko Gil-Alana $\mathbb{D}^{\mathrm{b}, \mathrm{c}}$ and Miguel Ángel Martin-Valmayor $\mathbb{D}^{\mathrm{c}, \mathrm{d}}$

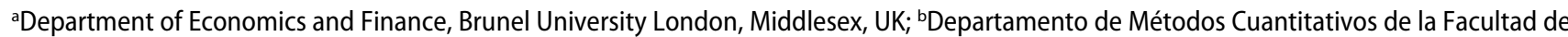 \\ Ciencias Económicas y Empresariales, University of Navarra, Pamplona, Spain; 'Universidad Francisco de Vitoria, Madrid, Spain; ${ }^{\text {dUniversidad }}$ \\ Complutense de Madrid, Madrid, Spain
}

ABSTRACT

This note examines the stochastic behaviour of US monthly 10-year government bond yields. Specifically, it estimates a fractional integration model suitable to capture both persistence and non-linearities, these being two important properties of interest rates. Two series are analysed, one from Bloomberg including end-of-the-month values over the period January 1962-August 2020, the other from the ECB reporting average monthly values over the period January 1900-August 2020. The estimation results indicate that both are highly persistent and exhibit non-linearities, the latter being more pronounced in the case of the ECB series. Also, there is no conclusive evidence of the presence of structural breaks.

\section{KEYWORDS}

Long-term interest rates; government bond yields; fractional integration; persistence; non-linearities

JEL CLASSIFICATION C22; E43

\section{Introduction}

Two important properties of interest rates are their high degree of persistence and the presence of non-linearities. The former has implications for the effectiveness of monetary policy and the empirical relevance of different theories such as consumption-based asset pricing models and the Fisher effect. The latter has become even more relevant in the new economic environment characterized by unconventional monetary policy and the so-called zero lower bound (ZLB) for interest rates. Therefore, it is crucial to adopt a modelling approach that can capture both. Earlier studies were normally based on the I $(0) / I(1)$ dichotomy and on a linear framework. For instance, Cox, Ingersoll, and Ross (1985) characterized the short-term nominal interest rate as a stationary and mean-reverting $\mathrm{I}(0)$ process, whilst Campbell and Shiller (1987) concluded that it exhibits a unit root and therefore is an $\mathrm{I}(1)$ process, which implies a lack of mean reversion (namely, shocks to interest rates have permanent effects).

Since unit root tests are well known to have very low power against fractional alternatives (Diebold and Rudebush 1991; Hassler and Wolters 1994; Lee and Schmidt 1996, etc.), a number of subsequent studies have used a fractional integration framework to analyse the behaviour of interest rates. For instance, Lai (1997), Phillips (1998) and Tsay (2000) found that it is appropriate for US real interest rates (see also Barkoulas and Baum 1997; Meade and Maier 2003; Gil-Alana 2004a, 2004b), and Couchman et al. (2006) presented similar evidence for 16 countries. Caporale and Gil-Alana (2009) reported that in the case of the Federal Funds effective rate the fractional integration parameter is sensitive to the specification of the error term, whilst Caporale and Gil-Alana $(2016,2017)$ obtained evidence of long memory and fractional integration and cycles for the Euribor and the Fed Funds rate, respectively.

The most recent literature has also argued that fractional integration is very much related to non-linearities (see Granger and Hyung 2004, etc.) and that these should also be taken into account when modelling interest rates. Therefore, the present note estimates a fractional integration model allowing for both persistence and non-linearities to investigate the stochastic behaviour of US monthly 10-year government bond yields; the possible presence of structural breaks is also examined. Below, Section 2 discusses the data and the empirical 
analysis, and Section 3 offers some concluding remarks.

\section{Data and empirical results}

We examine two monthly series for US 10-year Government Benchmark bond yields. The first (.USGG10YR Index) includes end-of-the-month values and has been obtained from Bloomberg over the period January 1962 - August 2020. The second reports instead average monthly values; the data source in this case is the European Central Bank (ECB) database, and the sample period is January 1900 - August 2020. These two series are plotted in Figures 1 and 2 respectively. In both cases it is apparent that long-term rates, initially relatively low, peaked in the 1980s before falling again.

The estimated non-linear model, as in Cuestas and Gil-Alana (2016), is the following:

$$
\mathrm{Y}_{\mathrm{t}}=\sum_{\mathrm{i}=0}^{\mathrm{m}} \theta_{\mathrm{i}} \mathrm{P}_{\mathrm{iT}}(\mathrm{t})+\mathrm{X}_{\mathrm{t}},(1-\mathrm{L})^{\mathrm{d}} \mathrm{X}_{\mathrm{t}}=\mathrm{u}_{\mathrm{t}}, \mathrm{t}=1,2, \cdots
$$

where $y_{t}$ is the observed time series, and $\mathrm{P}_{\mathrm{iT}}$ are the Chebyshev time polynomials defined as:

$$
\begin{aligned}
P_{0, T}(t) & =1, P_{i, \gamma}(t)=\sqrt{2} \cos (i \pi(t-0.5) / T), t \\
& =1,2, \cdots, T ; i=1,2, \cdots,
\end{aligned}
$$

where $\mathrm{m}$ indicates the degree of non-linearity. Thus, the higher $\mathrm{m}$ is, the less linear the approximated deterministic component is (see Hamming 1973; Smyth 1998). Bierens (1997) and Tomasevic, Tomasevic, and Stanivuk (2009) argue that it is possible to approximate highly non-linear trends with rather low degree polynomials. In this context, if $\mathrm{m}=0$ the specification contains only an intercept; if $\mathrm{m}=1$ a linear time trend is also included, and if $\mathrm{m}>1$, non-linearities are allowed. When estimating the model given by (1) we set $m=3$, thus capturing non-linearities in the series if $\theta_{2}$ and/or $\theta_{3}$ are statistically significant. We also assume that the errors are autocorrelated to allow for some degree of weak dependence. However, instead of using a standard AutoRegressive Moving Average (ARMA)

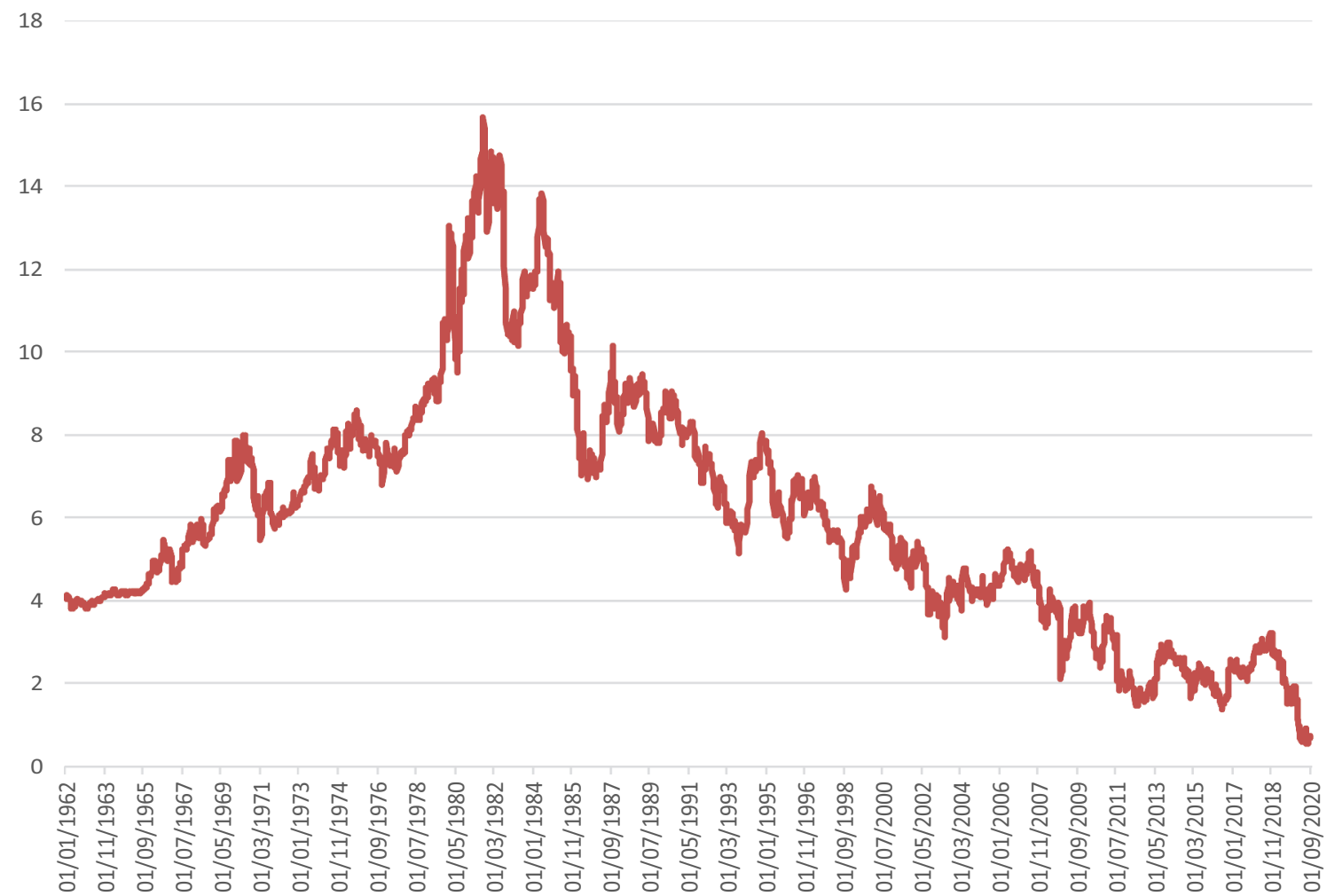

Figure 1. 10-year US Bond yield (.USGG10Y index). Source: Bloomberg. 


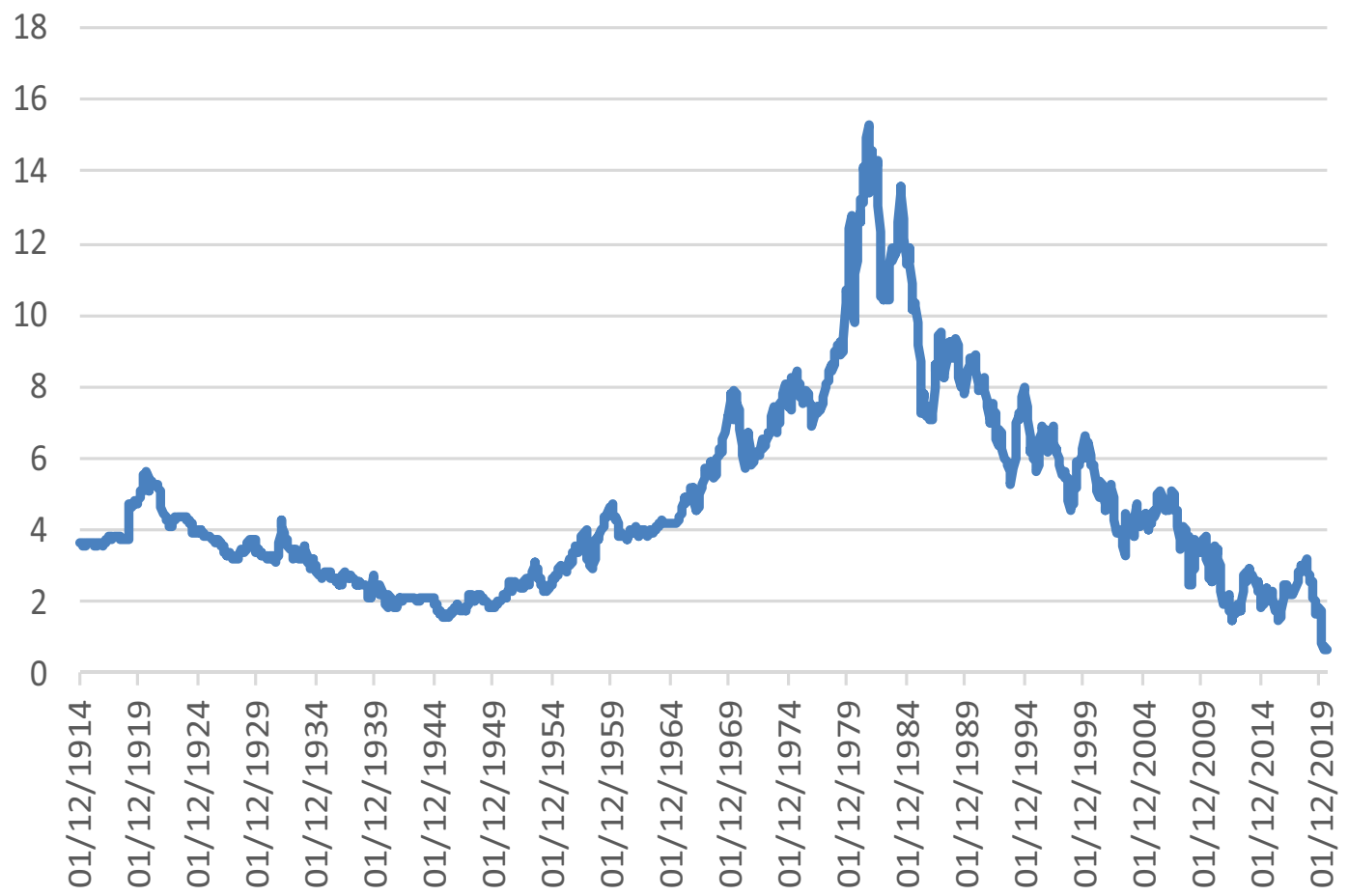

Figure 2. 10-Yr US Bond yield (average of monthly observations). Source: ECB.

model, we follow the non-parametric approach of Bloomfield (1973) that has been shown to work well in the context of fractional integration (see Gil-Alana 2004c).

Table 1 displays the results. The fractional differencing parameter $\mathrm{d}$ is estimated to be equal to 0.84 and 0.83 for the Bloomberg and ECB monthly series, respectively, and in both cases, the values in the confidence intervals are strictly smaller than 1, which supports the hypothesis of mean reversion. This is consistent with the findings of other studies on interest rates (Gil-Alana and Moreno 2012; Abbritti et al. 2016; etc.). In the case of the Bloomberg series, the four deterministic coefficients are statistically significant, which implies nonlinear behaviour. However, in the case of the ECB series with average values only $\theta_{0}$ and $\theta_{3}$ are found to be significant, which indicates a lower degree of non-linearities.
We have also investigated the possible presence of structural breaks in the series of interest by carrying out both the Bai and Perron (2003) and Gil-Alana (2008) tests, the latter having been specifically designed for the case of fractional integration. The two sets of results were very similar, in both cases two breaks being found in the Bloomberg series (in September 1981 and September 1987) and three in the ECB series (in December 1920, November 1945 and September 1981). Table 2 reports the estimates of $\mathrm{d}$ for each subsample based on the assumption of white noise errors. Similar results were obtained with autocorrelated disturbances. It can be seen that, given the wide confidence intervals, the results are not conclusive, namely the I(1) hypothesis cannot be rejected in the majority of cases. Specifically, for the Bloomberg series, it cannot be rejected for any of the three subsamples, whilst in the case of the ECB series the same holds for the first two

Table 1. Estimates of the Non-linear I(d) Model.

\begin{tabular}{|c|c|c|c|c|c|}
\hline Time Series & $d$ & $\theta_{0}$ & $\theta_{1}$ & $\theta_{2}$ & $\theta_{3}$ \\
\hline $\mathrm{Bl}$ & 0 & $5.7635(3.1$ & $1.7422(1.6$ & $-1.9333(-3.03)$ & $-1.0016(-2.20)$ \\
\hline ECB monthly 10-year bond yield da & $0.83(0.78,0.89)$ & $2.9648(2.08)$ & $-1.0753(-1.28)$ & $-0.6461(-1.27)$ & $1.741(4.80)$ \\
\hline
\end{tabular}

In bold, significant coefficients at the $5 \%$ level. In parentheses, in columns $3-6$, the associated t-values. 
Table 2. Sub-sample analysis (white noise errors).

\begin{tabular}{|c|c|c|c|}
\hline \multicolumn{4}{|c|}{ Bloomberg series } \\
\hline Subsamples & No terms & Intercept & Intercept and Trend \\
\hline January 1962/September 1981 & $1.05(0.96,1.16)$ & $0.99(0.91,1.11)$ & $0.99(0.90,1.11)$ \\
\hline October 1981/September 1987 & $0.97(0.83,1.16)$ & $1.05(0.90,1.27)$ & $1.05(0.90,1.26)$ \\
\hline October 1987/August 2020 & $0.99(0.92,1.08)$ & $1.00(0.91,1.11)$ & $1.00(0.91,1.11)$ \\
\hline \multicolumn{4}{|c|}{ ECB series } \\
\hline Subsamples & No terms & Intercept & Time trend \\
\hline January 1900/December 1920 & $1.02(0.93,1.13)$ & $1.05(0.96,1.17)$ & $1.05(0.96,1.17)$ \\
\hline January 1921/November 1945 & $0.98(0.90,1.08)$ & $1.11(0.99,1.24)$ & $1.10(0.99,1.24)$ \\
\hline December 1945/September 1981 & $1.17(1.09,1.28)$ & $1.16(1.07,1.29)$ & $1.16(1.07,1.29)$ \\
\hline October 1981/August 2020 & $0.94(0.88,1.02)$ & $1.20(1.10,1.32)$ & $1.19(1.09,1.32)$ \\
\hline
\end{tabular}

In bold significant coefficients at the $5 \%$ level. In parentheses, the $5 \%$ confidence intervals.

subsamples, while this hypothesis is rejected in favour of $d>1$ in the remaining two cases.

\section{Conclusions}

This note provides some evidence on the behaviour of US long-term interest rates, more specifically, the 10-year government bond yields. The fractional integration framework used is more general than the standard models based on the $\mathrm{I}(0)$ vs. I(1) dichotomy and can capture both persistence and non-linearities. The results show that indeed both these features are present in US long-term interest rates; also, the evidence of non-linearities is stronger for the Bloomberg series including end-of-themonth values than for the ECB one with average values. Further, break tests and sub-sample analysis do not provide conclusive evidence of the presence of structural breaks.

Since theory suggests that a variety of shocks such as preference, technology, fiscal and monetary shocks can generate persistence, it would be interesting to carry out additional research to investigate their relative importance. Furthermore, non-linear dynamics also have implications for the term structure of interest rates, namely that the relationship between short and long rates is no longer linear as in a standard cointegration model. Future work should also analyse such issues.

\section{Acknowledgments}

Luis A. Gil-Alana gratefully acknowledges the financial support from the Ministerio de Economía y Competitividad
(ECO2017-85503-R). Comments from the Editor and an anonymous reviewer are gratefully acknowledged.

\section{Disclosure statement}

No potential conflict of interest was reported by the authors.

\section{Funding}

This work was supported by the Ministerio de Economía y Competitividad [ECO2017-85503-R].

\section{ORCID}

Luis Alberiko Gil-Alana (D) http://orcid.org/0000-0002-57603123

Miguel Ángel Martin-Valmayor (iD http://orcid.org/00000003-4522-9960

\section{References}

Abbritti, M., L. A. Gil-Alana, Y. Lovcha, and A. Moreno. 2016. “Term Structure Persistence." Journal of Financial Econometrics 14 (2): 331-352. doi:10.1093/jjfinec/nbv003.

Bai, J., and P. Perron. 2003. "Computation and Analysis of Multiple Structural Change Models." Journal of Applied Econometrics 18 (1): 1-22. doi:10.1002/jae.659.

Barkoulas, J. T., and C. F. Baum. 1997. "Fractional Differencing Modeling and Forecasting of Eurocurrency Deposit Rates." The Journal of Financial Research 20: 355-372. doi:10.1111/j.1475-6803.1997.tb00254.x.

Bierens, H. J. 1997. "Testing the Unit Root with Drift Hypothesis against Nonlinear Trend Stationarity, with an Application to the U.S. Price Level and Interest Rate." Journal of Econometrics 81 (1): 29-64. doi:10.1016/S03044076(97)00033-X. 
Bloomfield, P. 1973. "An Exponential Model in the Spectrum of a Scalar Time Series.” Biometrika 60 (2): 217-226. doi:10.1093/biomet/60.2.217.

Campbell, J. Y., and R. J. Shiller. 1987. "Cointegration and Tests of Present Value Models." Journal of Political Economy 95: 1062-1088. doi:10.1086/261502.

Caporale, G. M., and L. A. Gil-Alana. 2009. "Persistence in US Interest Rates: Is It Stable over Time?" Quantitative and Qualitative Analysis in Social Sciences 3 (1): 63-77.

Caporale, G. M., and L. A. Gil-Alana. 2016. "Persistence and Cyclical Dependence in the Monthly Euribor Rate." Journal of Economics and Finance 40: 157-171. doi:10.1007/s12197014-9296-0.

Caporale, G. M., and L. A. Gil-Alana. 2017. "Persistence and Cycles in the US Federal Funds Rate." International Review of Financial Analysis 52: 1-8. doi:10.1016/j. irfa.2017.04.007.

Couchman, J., R. Gounder, and J. J. Su. 2006. “Long Memory Properties of Real Interest Rates for 16 Countries.” Applied Financial Economics Letters 2 (1): 25-30. doi:10.1080/ 17446540500396990.

Cox, J., J. Ingersoll, and S. Ross. 1985. "A Theory of Term Structure of Interest Rates." Econometrica 53: 385-408. doi:10.2307/1911242.

Cuestas, J. C., and L. A. Gil-Alana. 2016. "Testing for Long-Memory in the Presence of Non-Linear Chebyshev Polynomials." Studies in Nonlinear Dynamics and Econometrics 20 (1): 57-74.

Diebold, F. X., and G. Rudebush. 1991. "On the Power of the Dickey-Fuller Tests against Fractional Alternatives." Economic Letters 35: 55-160. doi:10.1016/0165-1765(91) 90163-F.

Gil-Alana, L. A. 2004a. "Long Memory in the Interest Rates in Some Asian Countries." International Advances in Economic Research 9: 257-267. doi:10.1007/BF02296174.

Gil-Alana, L. A. 2004b. "Long Memory in the US Interest Rate." International Review of Financial Analysis 13: 265-276. doi:10.1016/j.irfa.2004.02.009.

Gil-Alana, L. A. 2004c. "The Use of the Bloomfield (1973) Model as an Approximation to ARMA Processes in the Context of Fractional Integration." Mathematical and
Computer Modelling 39: 429-436. doi:10.1016/S08957177(04)90515-8.

Gil-Alana, L. A. 2008. "Fractional Integration and Structural Breaks at Unknown Periods of Time." Journal of Time Series Analysis 29 (1): 163-185. doi:10.1111/j.14679892.2007.00550.x.

Gil-Alana, L. A., and A. Moreno. 2012. "Uncovering the US Term Premium: An Alternative Route." Journal of Banking and Finance 36 (4): 1181-1193. doi:10.1016/j. jbankfin.2011.11.013.

Granger, C. W., and N. Hyung. 2004. "Occasional Structural Breaks and Long Memory with an Application to the S\&P 500 Absolute Stock Returns.” Journal of Empirical Finance 11 (3): 399-421. doi:10.1016/j.jempfin.2003.03.001.

Hamming, R. W. 1973. Numerical Methods for Scientists and Engineers. UK: Dover.

Hassler, U., and J. Wolters. 1994. "On the Power of Unit Root Tests against Fractional Alternatives.” Economics Letters 45: 1-5. doi:10.1016/0165-1765(94)90049-3.

Lai, K. S. 1997. "Long Term Persistence in Real Interest Rate. Some Evidence of a Fractional Unit Root." International Journal of Finance and Economics 2: 225-235. doi:10.1002/ (SICI)1099-1158(199707)2:3<225::AID-IJFE49>3.0.CO;2-C.

Lee, D., and P. Schmidt. 1996. "On the Power of the KPSS Test of Stationarity against Fractionally Integrated Alternatives." Journal of Econometrics 73: 285-302. doi:10.1016/0304-4076(95)01741-0.

Meade, N., and M. R. Maier. 2003. "Evidence of Long Memory Is Short Term Interest Rates." Journal of Forecasting 22: 553-568. doi:10.1002/for.873.

Phillips, P. C. B. 1998. "Econometric Analysis of Fisher's Equation." Cowles Foundation Discussion Paper 1180. Yale University.

Smyth, G. K. 1998. Polynomial Approximation. Chichester, UK: John Wiley \& Sons.

Tomasevic, N., M. Tomasevic, and T. Stanivuk. 2009. "Regression Analysis and Approximation by Means of Chebyshev Polynomial." Informatologia 42 (3): 166-172.

Tsay, W. J. 2000. "The Long Memory Story of the Real Interest Rate.” Economics Letters 67: 325-330. doi:10.1016/S01651765(99)00272-4. 